\title{
A new look in North-South biopartnerships
}

\section{Harvey Bialy}

Lorenzo Segovia, an investigator at the Institute of Biotechnology of the Autonomous National University of Mexico (IBT, UNAM) in Cuernavaca, recently visited the laboratories of Diversa, a San Diego, CA, biotechnology company specializing in recombinant approaches for accessing molecular diversity, to discuss using novel theoretical tools he has been developing to assist in rationally evolving enzymatic activities in vitro. After his seminar, the talk turned, naturally enough, to the subject of exotic cDNA libraries, and Lorenzo remembered that when he had been a postdoctoral fellow at the US National Institutes of Health (NIH; Bethesda, MD) working on the molecular biology of crystallins, he had a library of kangaroo eye cDNA made by Stratagene. At that moment, Marjory Snead, now Diversa's recombinant DNA librarian, introduced herself as the person who'd made it.

I tell this story, not so much as another example of the "small world of biotechnology," but rather to call attention to a relationship that breaks all the negative stereotypes associated with biodiversity prospecting ventures between the North and South, and is, I believe, an encouraging harbinger for their future. Unlike other collaborations, in which access to protected habitats has been granted to a pharmaceutical or biotechnology company interested in exploiting biodiversity (including Diversa's landmark agreement with the US government to bioprospect in Yellowstone National Park), the driving force behind the Diversa-IBT relationship was an interest on the part of scientists from both places in the structure and evolution of enzymes that function in extreme environments, and not in the commercialization of genetic resources.

It was from this mutual scientific interest, first recognized in 1995 at a thermophilic enzyme engineering symposium, that Xavier Soberon (now the director of the IBT) and Segovia began their discussions with Jay Short, Eric Mathur, and the other scientists at Diversa-discussions that resulted this month in the signing of a formal agreement that includes scientific consulting and capacity building, and also specifies the details of collaborations in commercial bioprospecting. It is doubtful that this last aspect, which has considerable political sensitivity in Mexico, could have been successfully concluded, or even nego- tiated, had not a strong, prior foundation, built on reciprocal intellectual respect and personal affection, been established over the preceding years.

Because the agreement between Diversa and UNAM allows the company limited access to federally protected, ecologically privileged sites identified from the proprietary databases of Mexico's National Commission on Biodiversity Use and Knowledge (CONABIO, www.conabio.gob.mx), it required and received the closest possible scrutiny from the ministry of the environment, which itself was being carefully watched by a number of nongovernmental environmental protection organizations.

While the very limited type of sampling used by direct cloning and expression approaches to bioprospecting has been widely viewed as completely benign, resolving issues regarding the real and perceived value of genes or microorganisms discovered in the course of the collaboration was much more complicated. The paperwork, lawyers' time, and meetings needed to satisfy all interested parties would have more than once derailed a less determined effort, and the final agreement is a testament to the perseverance of its drafters.

The multifaceted collaboration between the IBT, CONABIO, and Diversa is designed to foster a long-term relationship with the particular aim of establishing a laboratory for molecular biodiversity prospecting at the institute. This laboratory, which will be able to process environmental samples using proprietary technologies that Diversa will transfer to IBT scientists over time, will be in a position to initiate independent (as well as contractual) molecular prospecting schemes, design and implement enzyme screens and protein evolution protocols, and importantly, provide CONABIO with a hitherto unavailable collection of molecular microbial phylogenies to enrich its growing and detailed databases of Mexico's flora and fauna.

More immediately, the initial agreement, which runs for three years, provides for scientists from the IBT to accompany Diversa researchers to a selected sampling sites and to oversee and participate in a proscribed range of collection activities using the company's proprietary enrichment techniques, and for Diversa to teach IBT (and other UNAM) scientists its techniques for extracting nucleic acid and preparing efficient expression constructs.
The technology to be transferred includes preparation of environmental 16S RNA subunit libraries, 16S restriction fragment length polymorphism analysis, and automated molecular sequencing and molecular phylogenetic techniques, as well as the use and preparation of Diversa's "Bug Traps" (substrate derivatized beads incubated at the sample site to permit their colonization by microbes of interest).

The financial terms of the agreement provide for a modest fee to be paid to UNAM for each sample (enrichment culture, isolate, or nucleic acid extract taken or requested by Diversa), and a royalty on the net sales of any pharmaceutical or industrial product developed from the materials provided. These royalties will go to the development of the Protected Natural Areas, a program administered by Mexico's National Institute of Ecology (INE). As detailed in a separate agreement, initiated and negotiated as an important annex to the one with Diversa, INE and CONABIO will work with the IBT to assist in identifying collection sites, advise on legal aspects, and facilitate the acquisition of future collection permits.

Fostering this kind of interaction between national institutions is but one of the attractive and collatoral benefits of the Diversa partnership. Another is the increasing number of scientific collaborations being initiated between Cuernavaca and San Diego. In addition to Segovia's consulting relationship with Diversa, Lourival Possani, an expert in scorpion toxin biochemistry and biotechnology, has recently begun a joint research project with Diversa scientists to study the molecular diversity represented by the gut flora of this ancient insect. Finally, a newly installed video conference facility available to researchers at the IBT is likely to become an important tool for keeping the various parts of this collaboration connected.

Much has been written about the benefits to be derived from the constructive mining of genetic resources, and some widely noted first steps, such as the agreement between Merck and INBio (Costa Rica's National Institute for Biodiversity), have been taken in that direction. This newest joint venture, one actually worthy of that appellation, should set the standard by which the next generation of such relationships will be measured. 